\title{
EVALUATION OF GROOVING METHOD TO POSTPONE DEBONDING OF FRP LAMINATES IN WPC-FRP BEAMS
}

\author{
Shahin LALE AREFI ${ }^{\mathrm{a}}$, Morteza NAGHIPOUR ${ }^{\mathrm{b}}$, Zenonas TURSKIS $^{\mathrm{c}}$, Mehdi NEMATZADEH $^{\mathrm{d}}$ \\ ${ }^{a}$ Department of Civil Engineering, Shomal University, P. O. Box 731, Amol, Iran \\ ${ }^{b}$ Faculty of Civil Engineering, Babol University of Technology, 47148-71167 Babol, Iran \\ ${ }^{c}$ Civil Engineering Faculty, Department of Construction Technology and Management, \\ Vilnius Gediminas Technical University, Saulètekio al. 11, 10223 Vilnius, Lithuania \\ ${ }^{d}$ Department of Civil Engineering, Mazandaran University, P.O. Box 47416-13534, Babolsar, Iran
}

Received 03 Jul 2013; accepted 14 Nov 2013

\begin{abstract}
The use of lightweight construction material with high corrosion resistance and low cost plays an important role in the design and construction of marine structures such as waterfronts. One of the most common methods for strengthening the structures is composite fibre reinforced plastic (FRP) sheet that is used for member retrofitting including wood plastic composite (WPC). The WPC material is produced from wood and compressed resin, which has good mechanical properties as well as economic benefits. The main problem of WPC reinforced with FRP sheets is the debonding of the sheet from WPC surface, which leads to premature and non-economic failure in members. One of the existing methods to solve this problem is surface preparation. However, surface preparation of wood plastic composite has some additional problems, such as operational cost, environmental pollution, etc. Therefore, to avoid debonding, another method has been used, known as the grooving method at the lower parts of beams. The laboratory used 50 I-shaped specimens with the same geometrical and mechanical properties. Initially, some slots such as longitudinal, transverse and diagonal grooves were created on the surface of specimens and filled by an epoxy. All beams were armed using one or two layers of GFRP sheets embedded at the lower part and were tested under four-point flexural loading. Grooves of different shapes, various widths and depths as well as the number of reinforcement layers were determined for considering their effect on the beam's behaviour. The results expressed that the debonding of FRP sheets can be delayed by selecting the longitudinal grooves with certain width and depth, which also leads to resistance improvement.
\end{abstract}

Keywords: wood plastic composite, grooving method, debonding, flexural strength, composite FRP sheets, beam, reinforced.

Reference to this paper should be made as follows: Lale Arefi, S.; Naghipour, M.; Turskis, Z.; Nematzadeh, M. 2014. Evaluation of grooving method to postpone debonding of FRP laminates in WPC-FRP beams, Journal of Civil Engineering and Management 20(2): 237-246. http://dx.doi.org/10.3846/13923730.2013.878379

\section{Introduction}

In the design and construction of waterfront structures, there is a need for development of a corrosion resistant, lightweight, cost effective and environmentally friendly structural material. In comparison to onshore structures, these structures always have a shorter life cycle.

Typically, such materials as steel, concrete and wood are used to build waterfront structures. As they are always exposed to damage such as corrosion and erosion, some parts require retrofitting and replacement to ensure health and durability of the structures. Thus, a lightweight option with high corrosion resistance and low cost is important for the design and construction of such structures as waterfronts. This might be the reason for the growing popularity of Wood Plastic Composites (WPCs), which are lightweight and resistant to deterioration and corrosion. As WPCs are obtained combining wood and plastic appendage, their recyclability is one of the most important advantages compared to traditional materials (Simonsen 1995; Lopez-Anido, Xu 2002; Ballerini 2004). An additional advantage is that a portion of WPCs can be produced from recycled plastic and wood waste. Hence, WPCs are used for some secondary waterfront structures, such as decks and rails. In order to use these materials as the main structural component, their properties and behaviours should be accurately considered. Modification of mechanical and physical properties of WPCs can lead to development of an industrial and non-deformable product.

Reinforcement of structural components has become one of the main concerns for researchers. It should be done in a way that would allow complete use of all potential members and the resistance factor. In recent years, fibre reinforced plastic (FRP) composite material has been widely used in retrofit and rehabilitation of buil- 
dings and bridges due to its anti-corrosive, lightweight, ease of cutting and construction properties as well as high strength-to-weight ratio, high elastic modulus and high resistance to environmental degradation factors.

A number of researchers have applied these materials to strengthen the structures or wood framing members (Ogawa 2000; Dura et al. 2005). Li et al. (2009) verified a flexural theory of retrofitted wood beams using the carbon fibre reinforced plastic (CFRP) composite material through a four-point bending test. Details of the flexural strength and mid-span vertical displacement of the CFRP-retrofitted wood beams with the performance of the CFRP sheets adhered to the tensile side are available in their report. Using experimental and theoretical methods, effectiveness of glass fibre-reinforced polymer into the vibration damping of glulam beams strengthened with GFRP was investigated by Naghipour et al. (2005). Recent studies have shown that wooden structures reinforced with FRP composites have found applications in civil engineering including bridges, infrastructure applications, reinforced railroad ties, and repair of wood piles (Taheri et al. 2005; Gilfillan et al. 2003; Borri et al. 2005; Lopez-Anido et al. 2003; Fiorelli, Alves Dias 2003; Lopez-Anido, Karbhari 2000; Dagher et al. 2002; Lopez-Anido, Xu 2002; Pantelides et al. 2010). In recent years many studies have been implemented in the context of debonding phenomenon and the various methods such as surface preparation for its postponing. Nonetheless, it is still considered the most important issues on FRP that seem to have attracted many researches. Debonding problems stand as a critical barrier against a wide range of use of FRP composites in structural strengthening and repair applications (Buyukozturk et al. 2004). Toutanji and Ortiz (2001) used the sand and water spray system for surface preparation. The results indicate that the sample surface, which was roughened using the spraying system, had a more cohesive resistance compared to the sample that was roughened by conventional sand. In the same year, Galecki et al. (2001) evaluated the hardness measure and unevenness of concrete surface in cohesive strength; additionally, water jet system was examined for roughen. Finally, the results showed that high-pressure water jets increased the cohesive strength of specimens up to approx. $10 \%$ compared to specimens without surface preparation.

By the same token, Mostofinejad and Mahmoudabadi (2010) used the grooving method for surface replacement. The results showed that debonding from the plate surface was delayed or completely prevented in most cases. Experimental studies of recent years have shown that failure modes for WPC beams reinforced with FRP sheet are multiple; however, in a general division, they are divided into moment failure, shear and debonding ruptures, and can be expressed as (Naghipour et al. 2011):

1. Moment failure by rupture of FRP sheet;

2. Moment failure by crushing of WPC;

3. Shear failure;

4. FRP sheet debonding of the WPC.
Naghipour et al. (2013) used longitudinal groove for attaching GFRP sheet to WPC surface. Finally, the result showed that the use of longitudinal grooves resulted in resistance improvement. One of the fundamental problems in beams strengthened by FRP sheet is the premature failure that leads to sudden debonding of the sheets before reaching their ultimate strength. The main reason for this early failure is unsuitable preparation of the surface of beams, on which that FRP composite is installed. Accordingly, preparation has to be done before connecting the FRP composite to WPC to eliminate poor surfaces and make an appropriate structure for FRP installation. In order to have a better view of this subject, a WPC connection to FRP is considered.

WPC/FRP bond joints, such as those in FRPstrengthened WPC structural members, can be idealised as a three-layered material system consisting of WPC, epoxy and FRP. In such system, crack can propagate in five regions - bulk WPC, FRP sheet, bulk epoxy, the interface between WPC and epoxy, and the interface between epoxy and FRP (Fig. 1). It is now known that debonding may occur as one of five possible modes as illustrated in Figure 1. They are namely: (1) FRP delamination; (2) FRP/adhesive separation; (3) adhesive decohesion; (4) adhesive/WPC separation; and (5) WPC substrate fracture. The five failure modes can be broadly classified as two classes of failure: (a) material decohesion and (b) interface fracture. Failures (1), (3), and (5) are considered material decohesion while failures (2) and (4) are considered interface fracture. Among the five failure modes, WPC delamination is one of the most prominent types of failure that increases the importance of further studies on this subject.

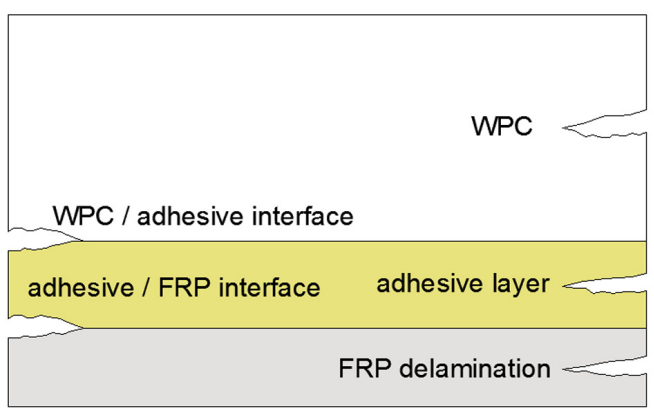

Fig. 1. Five possible failure modes

The purpose of this research is to evaluate the grooving method including various shapes such as diagonal grooves, transverse grooves and longitudinal grooves, in the debonding control of beams reinforced by FRP sheets; compare their treatment such as Forcedisplacement diagram; determine the failure mode and the ultimate failure load by changing the width, depth, and shapes of grooves; and determine the number of reinforcement layers. Fifty samples were tested to determine their flexural characteristics. Three of the beams considered were un-reinforced WPC beams and the others were reinforced with varying layers of GFRP. Wood plastic beams were reinforced at the bottom surface of the beam with 1 and 2 layers of GFRP composite sheets. All beams 


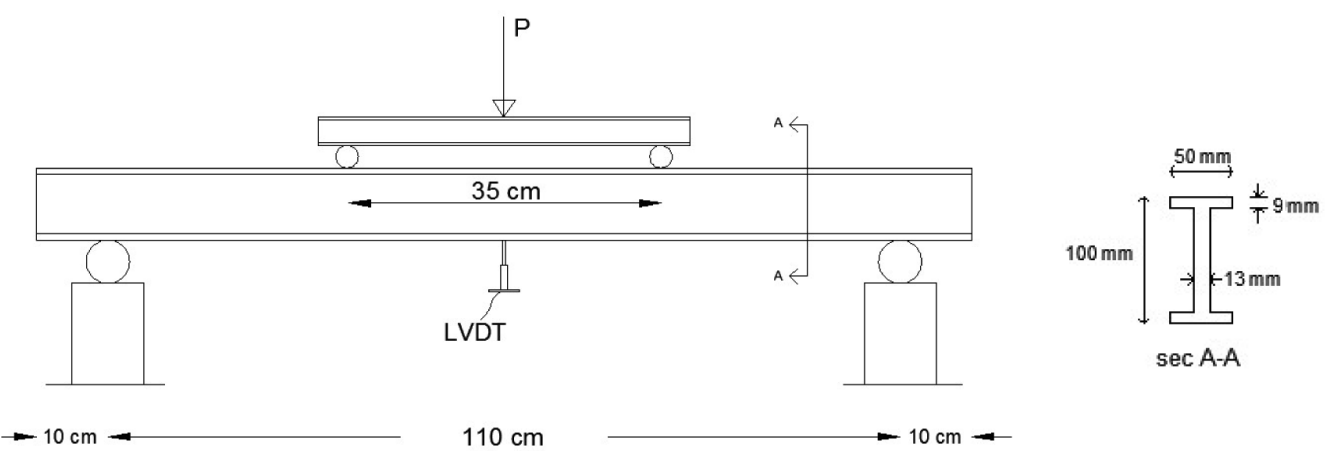

Fig. 2. Schematic representation of the four-point bending test

were subjected to a four-point bending test with the application of identical loads located at intervals equal to one-third of the span, according to the ASTM D198-94 (2005) standard. ASTM D 198-94 (2005) is the standard test method, which was utilized to determine the properties of wooden beams. Figure 2 shows a schematic view of the four-point bending test for the hybrid WPC-FRP beam together with the cross-section dimension used in this work.

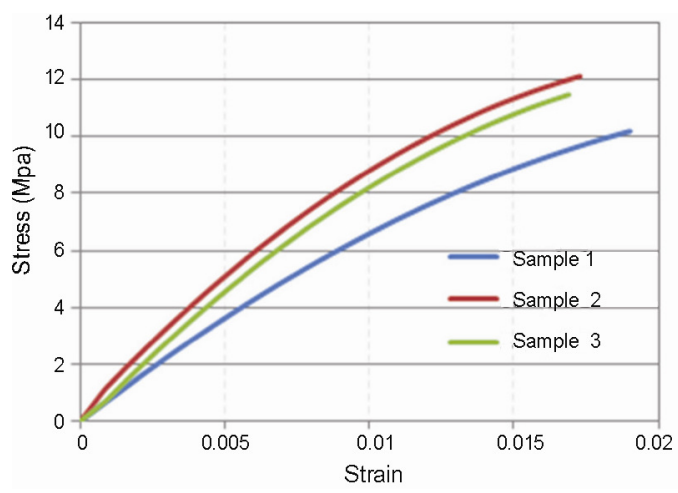

Fig. 3. Experimental tensile stress-strain relationships of WPC samples

Table 1. Material parameters and mechanical properties of WPC under tension test

\begin{tabular}{cccc}
\hline & $\begin{array}{c}\text { Initial modulus } \\
(\mathrm{MPa})\end{array}$ & $\begin{array}{c}\text { Ultimate } \\
\text { stress }(\mathrm{MPa})\end{array}$ & $\begin{array}{c}\text { Maximum } \\
\text { strain }\end{array}$ \\
\hline $\begin{array}{c}\text { Experimental } \\
\text { (average) }\end{array}$ & 1034.1 & 11.27 & 0.0177 \\
\hline
\end{tabular}

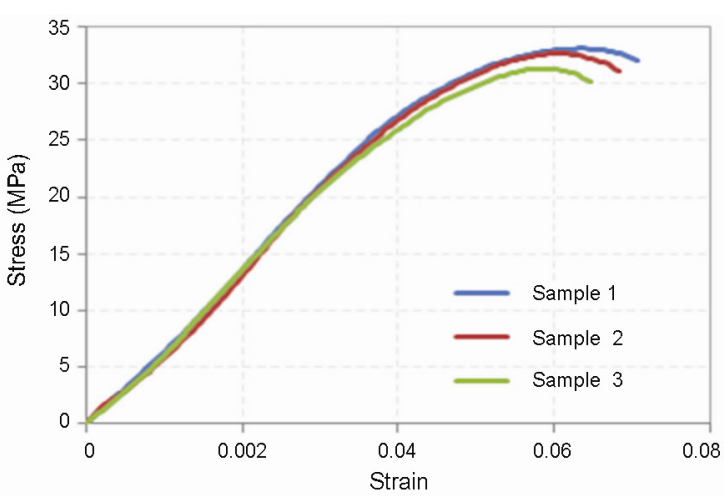

Fig. 4. Experimental compressive stress-strain relationships of WPC samples
Table 2. Material parameters and mechanical properties of WPC under compression test

\begin{tabular}{cccc}
\hline & $\begin{array}{c}\text { Initial modulus } \\
(\mathrm{MPa})\end{array}$ & $\begin{array}{c}\text { Ultimate } \\
\text { stress }(\mathrm{MPa})\end{array}$ & $\begin{array}{c}\text { Maximum } \\
\text { strain }\end{array}$ \\
\hline $\begin{array}{c}\text { Experimental } \\
\text { (average) }\end{array}$ & 601.2 & 32.65 & 0.0679 \\
\hline
\end{tabular}

\section{Specimen detail and material characteristics}

The specimens used in this study were $1300 \mathrm{~mm}$-long beams with. Flexural strengthening of the WPC beam specimens was ensured using GFRP sheets cut into 50-mm-wide and 1300-mm-long strips and then adhered to the bottom side of the test beams.

A number of coupon tests were established to obtain the mechanical properties and behaviour of WPC material in tension and compression as well as the mechanical properties of FRP in tension. The approach adopted to describe the properties of WPC was based on a series of standard tests. ASTM D638-03 (2004) is a standard test method to examine the stress-strain behaviour of WPC samples in uniaxial tension test. Moreover, the mechanical properties of WPC in compression were obtained through uniaxial compression test of ASTM D695-02a (2002). The tensile specimens were $183 \mathrm{~mm}$ long, with the centre section of $6 \mathrm{~mm}$ width by $3.5 \mathrm{~mm}$ thickness and $57 \mathrm{~mm}$ length. Also, cross-section dimensions of the compressive specimen were $12.7 \times 12.7 \mathrm{~mm}$ and $25.4 \mathrm{~mm}$ length. Figures 3 and 4 demonstrate the experimental stress-strain relationship of WPC in the tension and compression tests, respectively.

Ultimate stress, maximum strain and initial modulus of the WPC in tension and compression attained from the experimental tests, respectively, are shown in Tables 1 and 2. In these tables, the initial elastic modulus was computed at strain of 0.001 for tension and 0.005 for compression. In general, FRP composite material is composed of two basic segments, fibre and matrix (epoxy resin). Glass fibres are the reinforcing materials in the FRP composite to provide high strength and modulus of elasticity.

The specifications of the GFRP composites are presented in Table 3, which was provided by the supplier. This work involved external bonding of thin FRP sheets onto the tension zones of WPC beams using epoxy resins. The unidirectional fibre-reinforced polymers were glued to WPC with Epoxy adhesive using the wet application 
system. The specifications and testing standards of matrix (epoxy resin) used in this study are listed in Table 4, which was provided by the manufacturer.

Table 3. Specifications and testing standards of the matrix (epoxy resin)

\begin{tabular}{cccc}
\hline Items & Unit & Result & Test method \\
\hline Pot life & min & 70 & KS M 6030 \\
$\begin{array}{c}\text { Tensile } \\
\text { strength }\end{array}$ & $\mathrm{N} / \mathrm{mm}^{2}$ & 43.0 & KS M 3015 \\
$\begin{array}{c}\text { Flexural } \\
\text { strength }\end{array}$ & $\mathrm{N} / \mathrm{mm}^{2}$ & 87.2 & KS M 3015 \\
$\begin{array}{c}\text { Compressive } \\
\text { strength }\end{array}$ & $\mathrm{N} / \mathrm{mm}^{2}$ & 130 & $\begin{array}{c}\text { ASTM D695-02a } \\
(2002)\end{array}$ \\
$\begin{array}{c}\text { Compressive } \\
\text { modulus of } \\
\text { elasticity }\end{array}$ & $\mathrm{N} / \mathrm{mm}^{2}$ & $1.56 \times 10^{3}$ & $\begin{array}{c}\text { ASTM } \\
\text { D695-02a (2002) }\end{array}$ \\
\hline
\end{tabular}

Table 4. Specifications of FRP

\begin{tabular}{ccccc}
\hline $\begin{array}{c}\text { Type of } \\
\text { sheet }\end{array}$ & Thickness & $\begin{array}{c}\text { Fibre } \\
\text { strength }\end{array}$ & $\begin{array}{c}\text { Elastic } \\
\text { modulus }\end{array}$ & $\begin{array}{c}\text { Strain at } \\
\text { failure }\end{array}$ \\
\cline { 2 - 5 } & $(\mathrm{mm})$ & $(\mathrm{MPa})$ & $(\mathrm{GPa})$ & $\mathbf{( \% )}$ \\
\hline GFRP sheet & 0.16 & 2300 & 76 & 3.03 \\
\hline
\end{tabular}

\section{Testing layout and procedures}

The lamination process that can be used to fix the FRP sheet in WPC is manual. In this process, a surface primer is applied first to the WPC prepared surface to fill microcavities. After the primer is cured, the beam is eroded until the removal of a thin layer and then the grooves are created on specimens carefully. The grooves have to be cleaned from any dirt and dust by jet air.

The recommended resin is then mixed and applied to the WPC surface in a thin uniform layer using a roller. The epoxy resin consists of two parts of saturated A and $\mathrm{B}$, which are mixed at a ratio of 100:50 by weight. At this stage, the grooves are filled with a suitable epoxy to achieve a smooth and uniform surface. After complete filling of grooves, a fibre sheet (pre-impregnated or dry) is cut to the desired length and width and pressed to the WPC using a "bubble roller". This helps getting rid of entrapped air between fibres and resin and ensures the impregnation of the FRP sheet with resin. Once the ply is installed, a second layer of impregnating resin is applied. In the case of multiple plies, the process is repeated.

Wood-plastic reinforced beams are categorised in 13 major groups based on the type of surface preparation and the number of reinforced layers by FRP: A; B1; C1; D1; E1; F1; G1; B2; C2; D2; E2; F2; G2.

The description of specimen specifications is provided in Table 5.

As shown in Table 5, beams in group A were without strengthening, groups B1 to G1 were strengthened with a layer of FRP sheet and groups B2 to G2 were strengthened with two layers of FRP sheets. There were three test specimens in each group. All specimens were strengthened with GFRP sheets except for the specimens in group A.

Specimens in group A were used as reference beams and had no strengthening. They were intended for comparison with other specimens used in the laboratory. Groups B1 and B2, respectively, were strengthened with one and two layers of FRP and had no surface preparation. Specimens that were reinforced by surface preparation were classified in groups $\mathrm{C} 1$ and $\mathrm{C} 2$ (Fig. 5 (a)). Once a weak layer was taken from the beams, the specimens were cleaned using jet air in order to remove any constraints that would stand between the sheets and the beam surface. The other specimens were tested after subjection to alternative methods of surface preparation including transverse, diagonal, and longitudinal grooves. They were classified into groups D1-G1 with one reinforced layer and groups D2-G2 with two reinforced layers.

One alternative method of surface preparation used was transverse grooving (Fig. 5 (b)). The specification of this method is presented in Table 5. The grooves were then cleaned using jet air and later filled with epoxy resin.

Table 5. Specifications of test specimens

\begin{tabular}{|c|c|c|c|c|c|c|}
\hline \multirow{2}{*}{ Beam series } & \multirow{2}{*}{$\begin{array}{c}\text { Number of FRP } \\
\text { layers }\end{array}$} & \multirow{2}{*}{$\begin{array}{c}\text { Conventional surface } \\
\text { preparation }\end{array}$} & \multirow{2}{*}{ Alternative method } & \multicolumn{3}{|c|}{ Dimension of groove $(\mathrm{mm})$} \\
\hline & & & & Length & Width & Depth \\
\hline $\mathrm{A}$ & Un-reinforced & N.A. & - & - & - & - \\
\hline $\mathrm{B} 1$ & 1 & - & - & - & - & - \\
\hline $\mathrm{C} 1$ & 1 & Grinded & - & - & - & - \\
\hline D1 & 1 & - & Transverse grooves & 40 & 4 & 4 \\
\hline E1 & 1 & - & Diagonal grooves & 50 & 4 & 4 \\
\hline $\mathrm{F} 1$ & 1 & - & Longitudinal grooves & 1200 & 4 & 4 \\
\hline G1 & 1 & - & Longitudinal grooves & 1200 & 4 & 6 \\
\hline $\mathrm{B} 2$ & 2 & - & - & - & - & - \\
\hline $\mathrm{C} 2$ & 2 & Grinded & - & - & - & - \\
\hline D2 & 2 & - & Transverse grooves & 40 & 4 & 4 \\
\hline E2 & 2 & - & Diagonal grooves & 50 & 4 & 4 \\
\hline $\mathrm{F} 2$ & 2 & - & Longitudinal grooves & 1200 & 4 & 4 \\
\hline G2 & 2 & - & Longitudinal grooves & 1200 & 4 & 6 \\
\hline
\end{tabular}



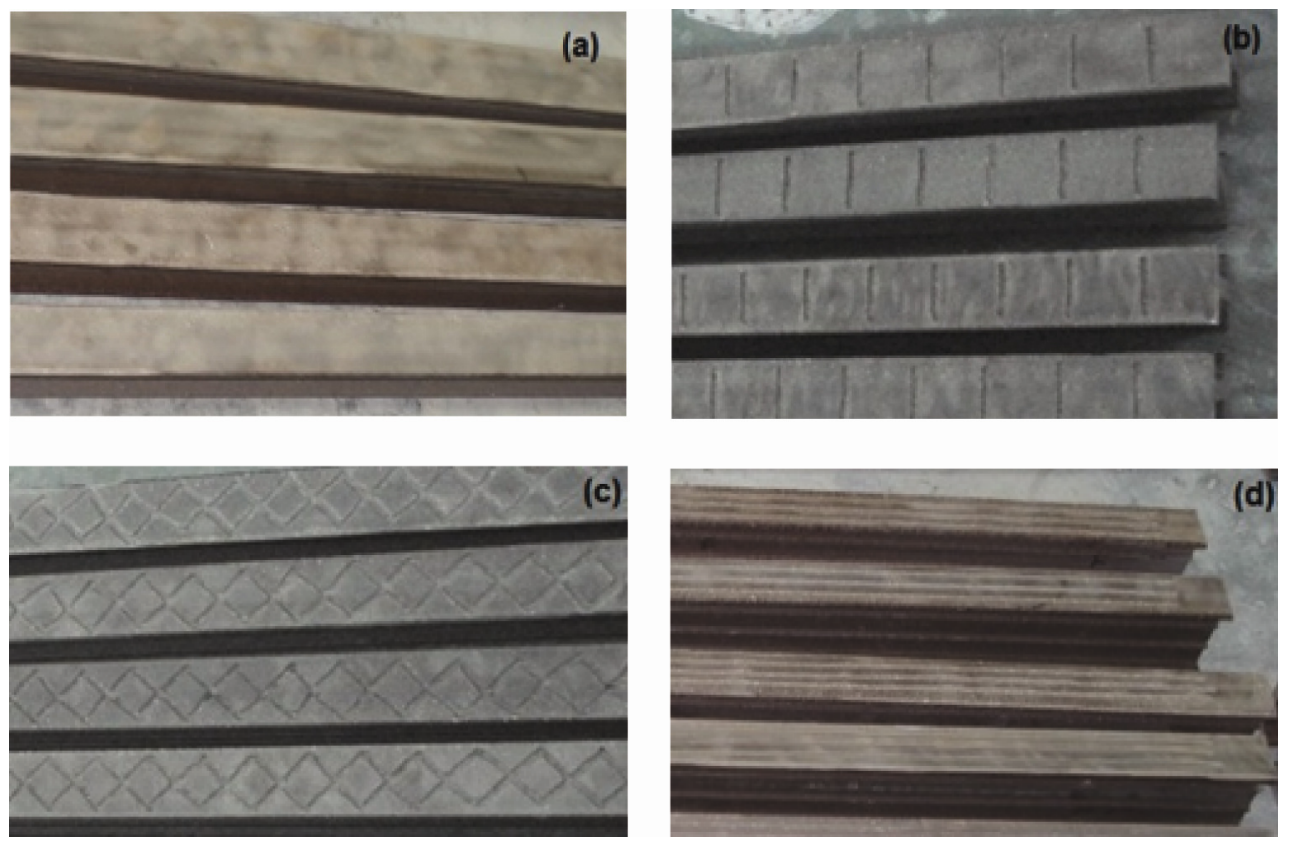

Fig. 5. Specimens in different shapes: (a) with surface preparation; (b) with transverse grooves;

(c) with diagonal grooves; (d) with longitudinal grooves

In addition to transverse grooving, in some specimens, diagonal grooves of $4 \mathrm{~mm}$ depth and $4 \mathrm{~mm}$ width at an angle of $45^{\circ}$ spaced $50 \mathrm{~mm}$ apart were made and later filled as described above Figure 5 (c). As shown in Figure $5(\mathrm{~d})$, the third type of grooving was also made in some specimens as the third type of alternative surface preparation. This involved longitudinal grooves of $4 \mathrm{~mm}$ width but with two different depths, i.e. 4 and $6 \mathrm{~mm}$. These were similarly cleaned and filled for strengthening with FRP sheets.

The prepared specimens were subjected to the fourpoint flexural loading test. To measure the midspan displacement in the specimens, one Linear Variable Differential Transducers (LVDT) was used and the load- displacement curves were plotted for the specimens for further analysis.

It needs to be mentioned that loading was continued up to the ultimate failure of the specimens.

\section{Experimental results}

The experimental specimens used in this study were WPC specimens without reinforcement, strengthened with GFRP sheets and subjected to four-point flexural loading tests. An analysis of the results for each of 13 groups was carried out and the relevant loaddisplacement diagrams were drawn. Each diagram in this study included three curves, which represented all specimens in that group.
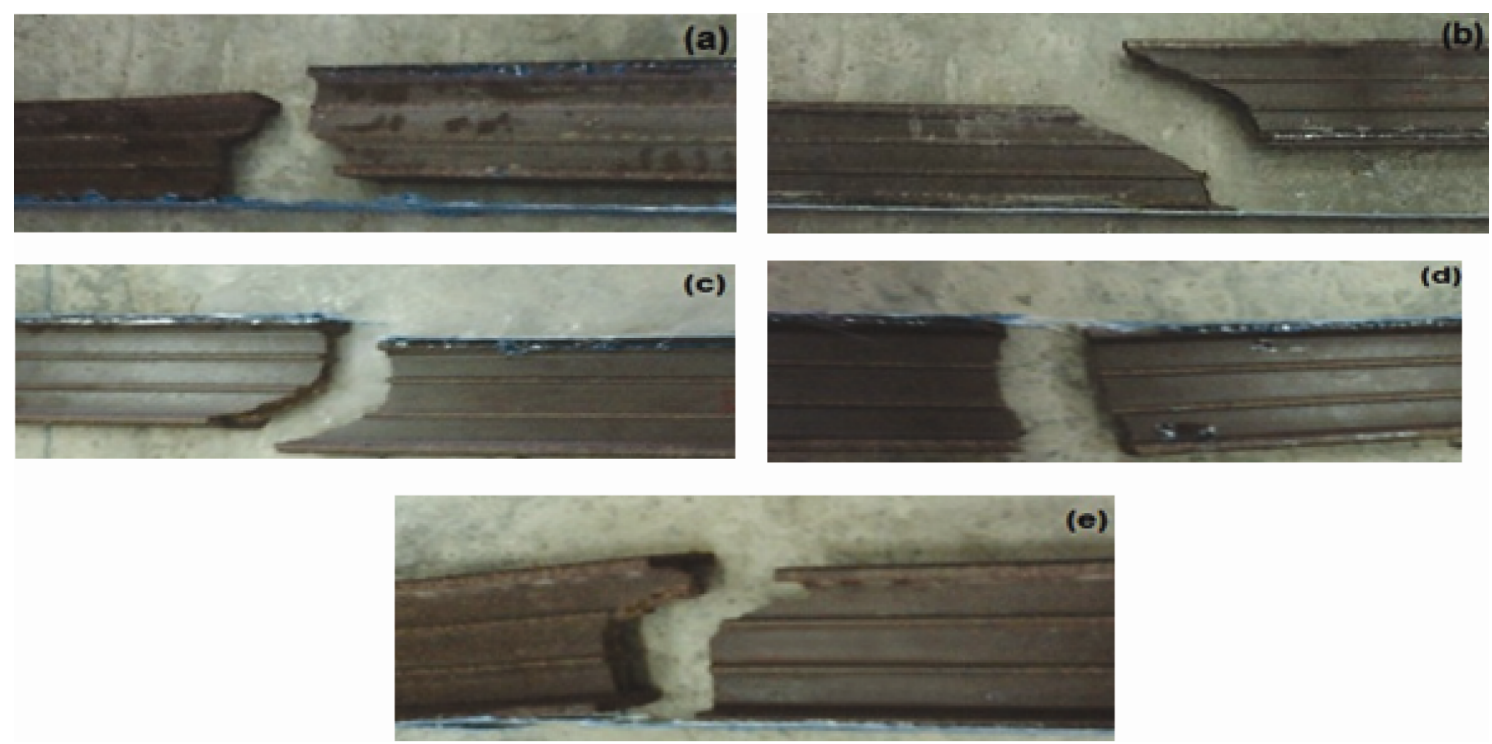

Fig. 6. Failure mode of the specimen beams strengthened in different groups: (a) without any surface preparation;

(b) with surface preparation; (c) transverse grooves; (d) diagonal grooves; (e) longitudinal grooves 


\subsection{Effect of WPC surface preparation}

The failure mode of the specimen A (un-reinforced) was a flexural failure as the tensile region reached the ultimate tensile strength. Figure 7 represents the load-displacement curves for a number of specimens in the group A. The specimens that had no surface preparation and were strengthened with one layer or even two layers of sheets, (groups B1 and B2) had a higher ultimate rupture strength than those in the group A due to their flexural strengthening with FRP sheets. Loading in these specimens was also continued until the ultimate failure point.

As Figure 6(a) provides, for the sheet to debond at the end part of the beam, the type of fracture and failure of the specimens attributed this beam group happened before reaching the ultimate strength and no rupture was detected in fibres. Figures 8 and 14 represent the loaddisplacement curves for a number of specimens in groups $\mathrm{B} 1$ and $\mathrm{B} 2$.

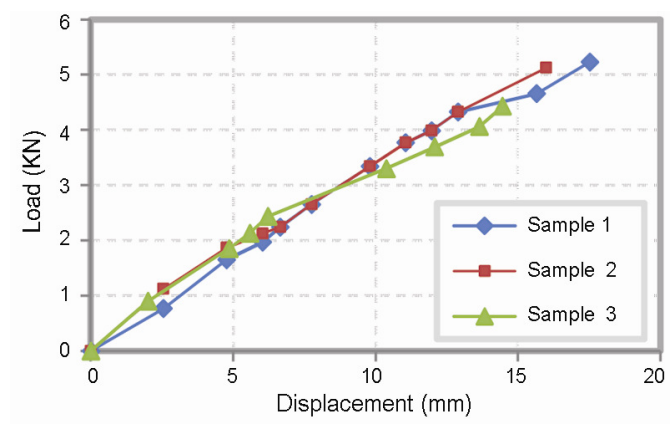

Fig. 7. Load-displacement curves for different specimens without strengthening

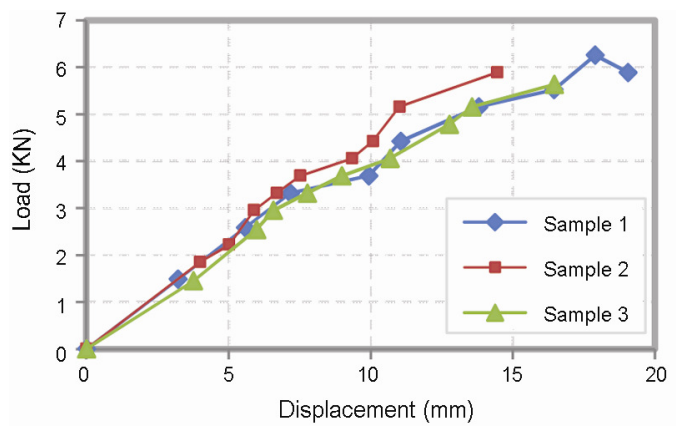

Fig. 8. Load-displacement curves for different specimens strengthened with one layer of GFRP but without surface preparation

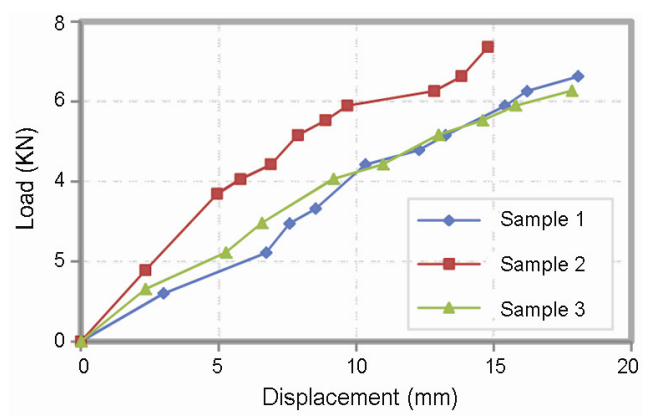

Fig. 9. Load-displacement curves for different specimens strengthened with one layer of GFRP and with surface preparation

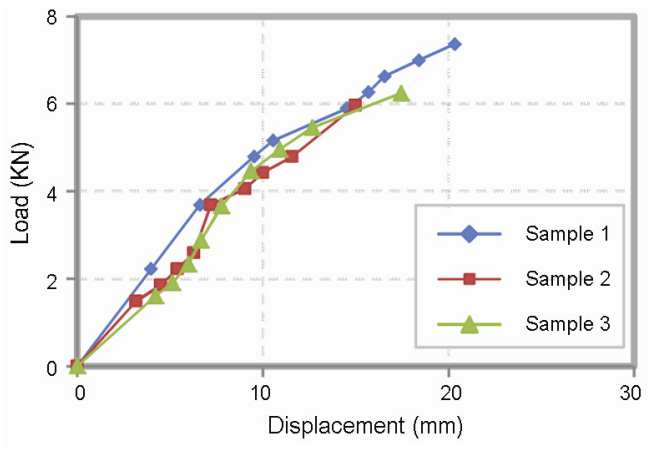

Fig. 10. Load-displacement curves for FRP-strengthened specimens with one layer of GFRP and with transverse grooves

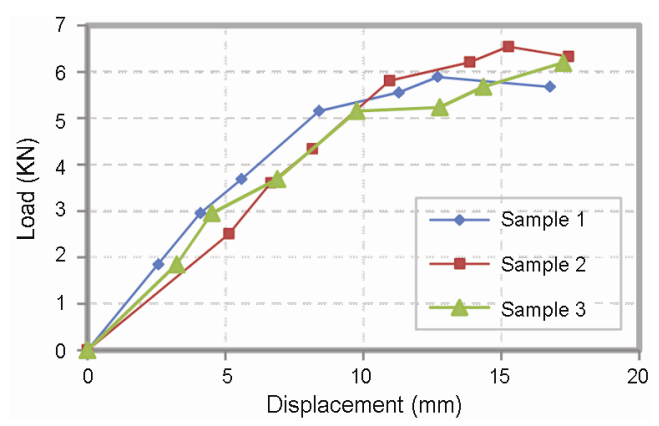

Fig. 11. Load-displacement curves for FRP-strengthened specimens with one layer of GFRP and with diagonal grooves

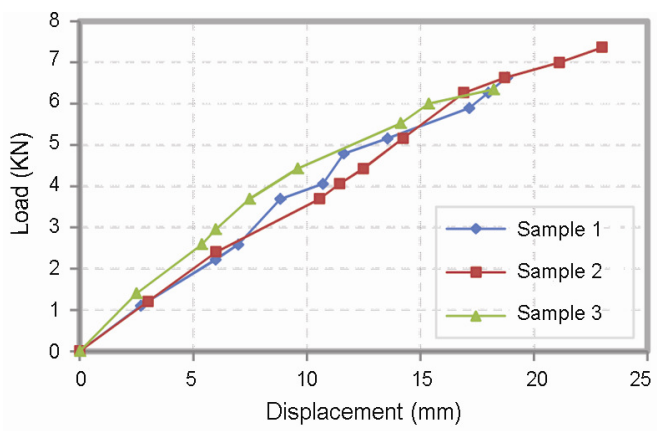

Fig. 12. Load-displacement curves for FRP-strengthened specimens with one layer of GFRP and with longitudinal grooves $4 \mathrm{~mm}$ deep

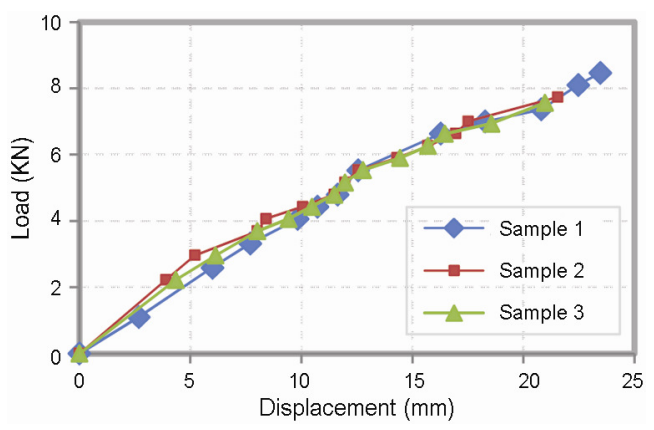

Fig. 13. Load-displacement curves for FRP-strengthened specimens with one layer of GFRP and with longitudinal grooves of $6 \mathrm{~mm}$ depth

Although in comparison to specimens without surface preparation the obtained ultimate failure strength was greater in the specimens with surface preparation prior to strengthening with polymer sheets, such as in 
groups $\mathrm{C} 1$ and $\mathrm{C} 2$, the sheet was separated from the surface in specimens with one reinforcing layer (group $\mathrm{C} 1$ ) due to insufficient connection between the plate and the WPC and failure to reach its ultimate strength. The beam reached its capacity only in one of the specimens with two reinforcing layers (Groups $\mathrm{C} 1$ ), but the debonding was also observed in other specimens (Fig. 6 (b)).

Figures 9 and 15 represent the load-displacement curves for a number of specimens in these groups. The comparison of Figures 8 and 9 reveal the effect of surface preparation when installing FRP sheets in specimens strengthened with one layer of GFRP. Also, this issue was observed in specimens strengthened with two layers of GFRP sheets (Figs 9 and 15).

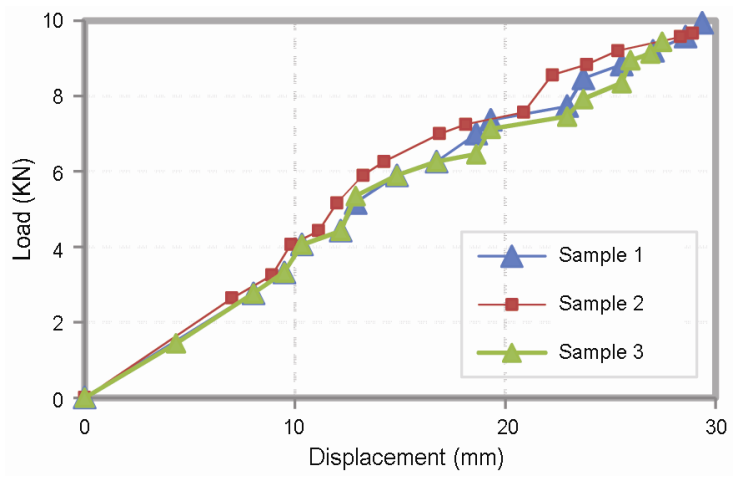

Fig. 14. Load-displacement curves for different specimens strengthened with two layers of GFRP but without surface preparation

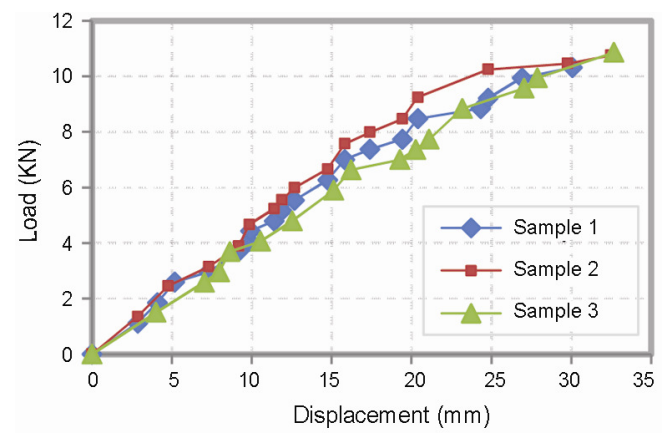

Fig. 15. Load-displacement curves for different specimens strengthened with two layers of GFRP and with surface preparation

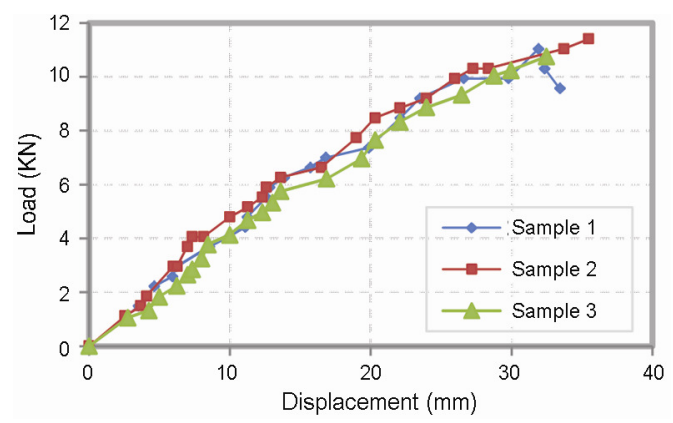

Fig. 16. Load-displacement curves for FRP-strengthened specimens with two layers of GFRP and with transverse grooves

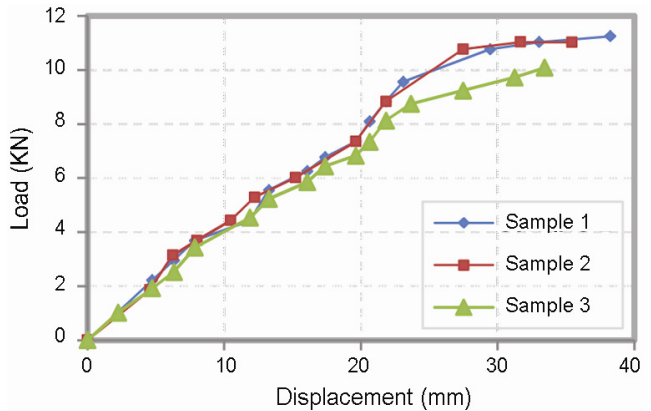

Fig. 17. Load-displacement curves for FRP-strengthened specimens with two layers of GFRP and with diagonal grooves

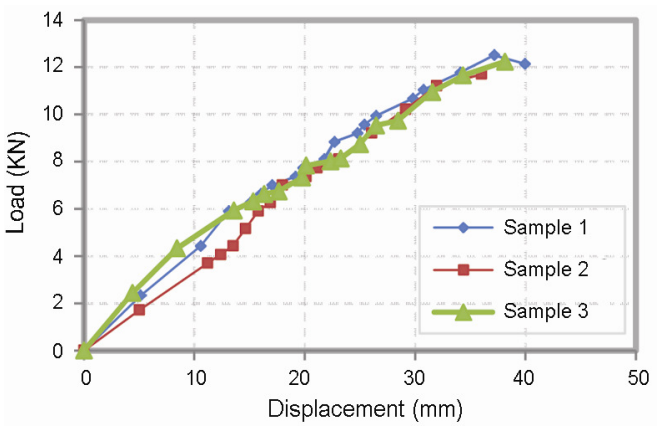

Fig. 18. Load-displacement curves for FRP-strengthened specimens with two layers of GFRP and with longitudinal grooves of $4 \mathrm{~mm}$ depth

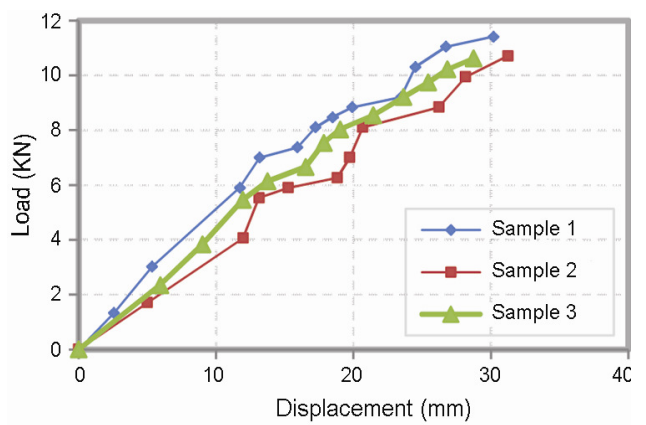

Fig. 19. Load-displacement curves for FRP-strengthened specimens with two layers of GFRP and with longitudinal grooves of $6 \mathrm{~mm}$ depth

\subsection{Effects of substitute methods of surface preparation}

The ultimate strength of the samples with transverse and diagonal grooves was close to the samples with surface preparation (slightly lower). The great depth that was considered for these grooves to reduce the area of the beam's lower flange as well as failure to align with the longitudinal stress may be the reasons for this proximity (Fig. 6(c) and Fig. 6(d)). The specimens had transverse and diagonal grooves, respectively. Their load displacement curves are shown in Figures 10 and 11.

In addition, the load-displacement diagram for reinforced specimens with two layers of FRP and transverse and diagonal grooves are shown in Figures 16 and 17.

In the specimens, for which longitudinal grooving methods were used instead of surface preparation, better performance was obtained and greater rupture strengths 
were obtained compared to specimens with conventional surface preparation (Fig. 6(e)).

The specimens with longitudinal grooves of different depths, i.e. 4 and $6 \mathrm{~mm}$, were attributed to groups $\mathrm{F}$ and $\mathrm{G}$.

Figures 12 and 13 show load-displacement curves for specimen groups F1 and G1, respectively. Loaddisplacement diagram is shown in Figures 18 and 19 for reinforced specimens with two layers of FRP sheets and longitudinal grooves. Generally, these specimens exhibited greater ultimate failure strengths than the specimens in other groups such that longitudinal grooves showed enhancement of the ultimate rupture strength to a considerable degree compared to conventional surface preparation. Figures 20 and 21 show the comparison between the load displacement curves of FRP strengthened specimens with conventional surface preparation and various configurations of grooves. The figure clearly shows the superiority of grooving technique to conventional surface preparation for the increase of both debonding failure load and its corresponding displacement.

\section{Discussion}

The value for the average rupture strength in specimens lacking strengthening was $4.93 \mathrm{KN}$. In this research, for WPC beams reinforced with one layer of FRP sheet, average rupture strengths without and with surface preparation were up to 5.80 and $6.75 \mathrm{KN}$, respectively. Hence, it can be concluded that due to the strengthening with FRP plates, rupture strength increased up to $18 \%$ and due to surface preparation, rapture strength increased up to $16 \%$. As for WPC beams that were reinforced with two layers of FRP sheet, their average rupture strengths without and with surface preparation was up to 9.67 and $10.63 \mathrm{KN}$, respectively, which shows the increase of $96 \%$ due to strengthening with FRP plates and $10 \%$ due to strengthening and surface preparation.

For WPC beams reinforced with one layer of FRP sheet and transverse and diagonal grooves, the average ultimate strength values were 6.52 and $6.21 \mathrm{KN}$. For WPC beams reinforced with two layers of FRP sheet and transverse and diagonal grooves, the average ultimate strength values were 10.96 and $10.79 \mathrm{KN}$.

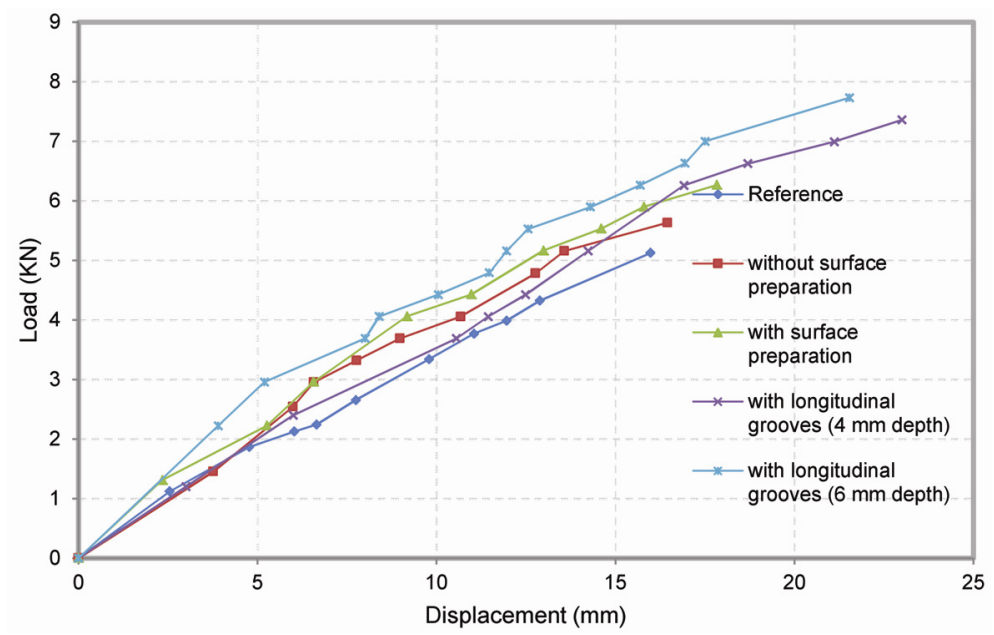

Fig. 20. Comparing the curves of load-displacement in reinforced specimen with one layer of GFRP

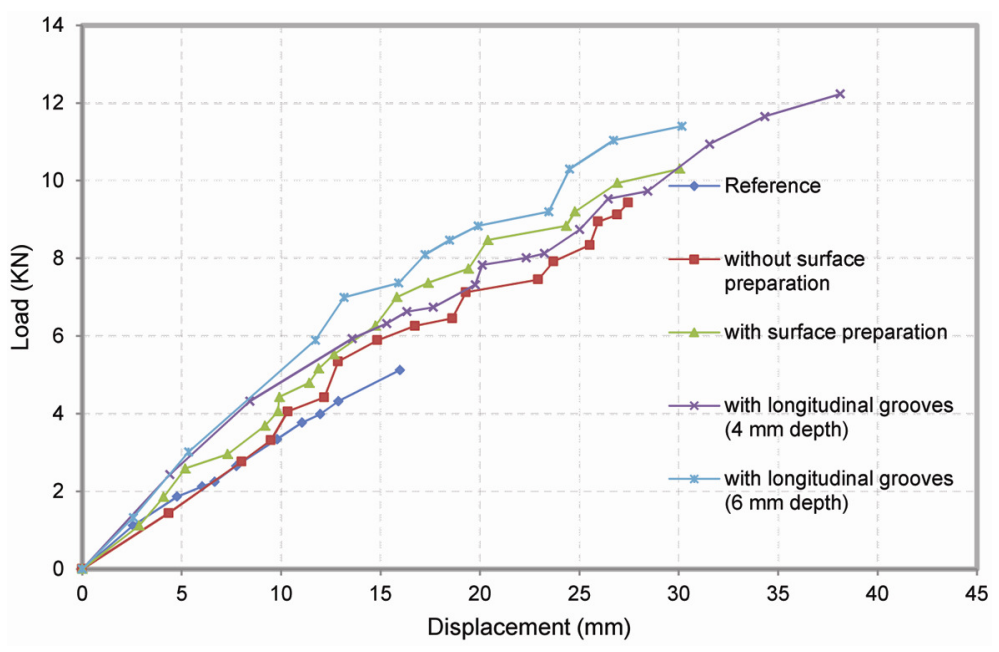

Fig. 21. Comparing the curves of load-displacement in reinforced specimen with two layers of GFRP 
Consequently, there is a very little difference between this strengthening technique and methods of surface preparation.

The use of longitudinal grooving in samples with one and two reinforcing layers with FRP sheets showed higher rupture strengths, compared to specimens without surface preparation. This was observed during the comparison of different groups (Figs 22 and 23).

The average rupture strengths in samples with one reinforcing layer with FRP sheets and longitudinal grooving at 4 and 6-mm depths were 6.78 and $7.74 \mathrm{kN}$, respectively, which represents an increase of $17 \%$ and $33 \%$ compared to those specimens without surface preparation. The result for these grooves in samples with two layers of FRP sheets was 12.15 and 10.91 , which represents an increase of $26 \%$ and $13 \%$ compared to specimens without surface preparation. To justify the postponing effect of grooving technique on the debonding of FRP sheets from WPC surface, it can be said that one major reason for the poor bonding of sheets and WPC surface is the lack of adequate contact area between these two surfaces. By eliminating this inadequacy and increasing the contact area between the epoxy resin and the sheet (along the stresses created in the sheet, which is longitudinal), higher rupture loadings are expected to be obtained. Longitudinal grooving creates the higher contact area required, delaying the debonding and creating a higher rupture loading capacity. The results show higher loading capacity in specimens with longitudinal grooves; this can be contributed to their contact area being parallel to interfacial bond stress between the FRP sheets and WPC substrate. It needs to be mentioned that the depths of 4 and $6 \mathrm{~mm}$ were only arbitrarily chosen, which could be varied in order to obtain the optimum depth with the highest possible ultimate strength.

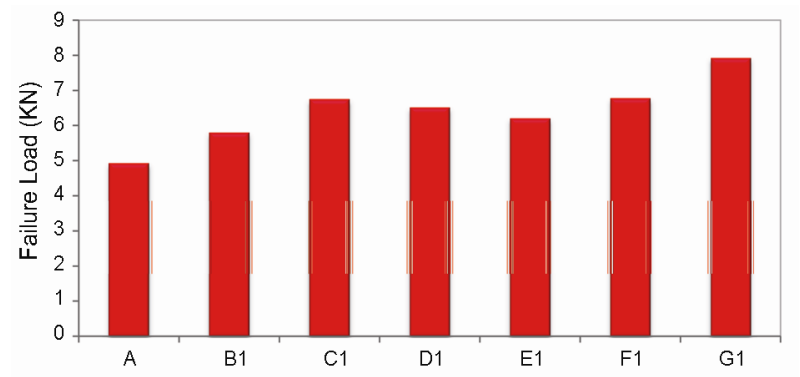

Fig. 22. Average ultimate failure loads of different groups of specimens with one layer of GFRP

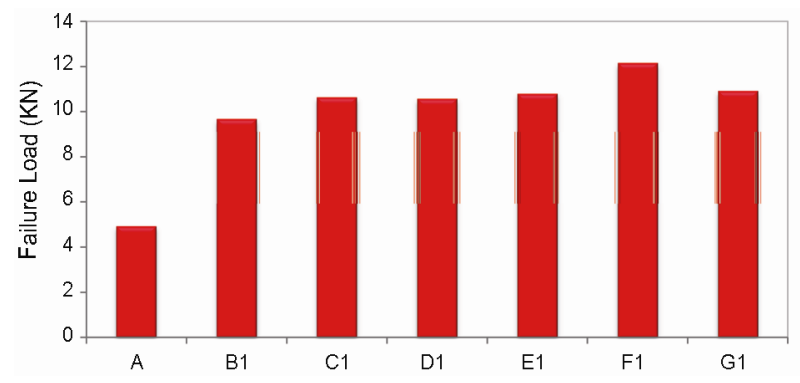

Fig. 23. Average ultimate failure loads of different groups of specimens with two layers of GFRP

\section{Conclusions}

Based on the analysis of results obtained from flexural strengthening of beams, their surface preparation, and the grooving methods used as a substitute method for "surface preparation" in this study, the following conclusions are drawn:

1. WPC surface preparation increased the ultimate failure strength up to $18 \%$ compared with the samples without the surface preparation. This percentage would be approx. $10 \%$ for the reinforced samples with two layers of FRP sheets. It is likely that the beam has not yet reached its ultimate strength and the complete debonding occurred.

2. Despite the fact that transverse and diagonal grooving, increases the contact area between the adhesive and WPC, the beam's strength is reduced due to the small difference between the flange thickness and depth of grooves, which could neutralise the increased strength.

3. Longitudinal grooving caused a considerable increase in ultimate rupture strength by increasing the contact area between the epoxy resin and the underlying WPC layer along the longitudinal stresses, so that longitudinal grooves of $4 \mathrm{~mm}$ depth caused an increase of $3 \%$ in the ultimate rupture strength in specimens with one layer of FRP and $22 \%$ in specimens with two layers of FRP as compared to specimens with only surface preparation. This increased the load capacity in specimens with one layer of FRP and longitudinal grooves of $6 \mathrm{~mm}$ depth up to $14 \%$, and $3 \%$ in specimens with two layers of FRP as compared to specimens with only surface preparation. These longitudinal grooves caused the strain in FRP sheets to reach its maximum value so that the sheet was ruptured. This indicates that longitudinal grooves with adequate depth may completely prevent debonding.

\section{References}

ASTM D695-02a. 2002. Standard test method for compressive properties of rigid plastics. American Society for Testing and Materials (ASTM), USA. 12 p.

ASTM D638-03. 2004. Standard test method for tensile properties of plastics. American Society for Testing and Materials (ASTM), USA. 4 p.

ASTM D198-94. 2005. Standard methods of static tests of lumber in structural sizes. American Society for Testing and Materials (ASTM), USA. 27 p.

Ballerini, A. 2004. Development of chemical additives from tall oil to improve the compatibility of wood-plastic composites [online], [cited 10 September 2013]. Available from Internet:

http://www.conicyt.cl/bases/fondef/PROYECTO/04/I/D0 4I1185.HTMLS

Borri, A.; Corradi, M.; Grazini, A. 2005. A method for flexural reinforcement of old wood beams with CFRP materials, Composites Part B: Engineering 36(2): 143-153. http://dx.doi.org/10.1016/j.compositesb.2004.04.013

Buyukozturk, O.; Gunes, O.; Karaca, E. 2004. Progress on understanding debonding problems in reinforced concrete and steel members strengthened using FRP composites, Construction and Building Materials 18(1): 9-19. http://dx.doi.org/10.1016/S0950-0618(03)00094-1 
Dagher, H. J.; Bragdon, M.; Lindyberg, R. F. 2002. Advanced fiber-reinforced polymer wood composites in transportation applications, Transportation Research Record 1814: 237-242. http://dx.doi.org/10.3141/1814-28

Dura, M.; Lopez-Anido, R. A.; Dagher, H. J.; Gardner, D. J.; O’Neill, S. R.; Stephens, K. L. 2005. Experimental behavior of hybrid wood-plastic composite-FRP-structural members for use in sustained loading applications, in The $8^{\text {th }}$ International Conference on Woodfiber-Plastic Composites, 23-25 May, 2005, Madison WI, USA, 189-193.

Fiorelli, J.; Alves Dias, A. 2003. Analysis of the strength and stiffness of timber beams reinforced with carbon fiber and glass fiber, Materials Research 6(2): 193-202. http://dx.doi.org/10.1590/S1516-14392003000200014

Galecki, G.; Maerz, N.; Nanni, A.; Myers, J. 2001. Limitations to the use of waterjets in concrete substrate preparation, in Proc. of American Waterjet Conference (WJTA 2001), 18-21 August, 2001, Minneapolis, Minnesota, USA. Paper No $35.11 \mathrm{p}$.

Gilfillan, J. R.; Gilbert, S. G.; Patrick, G. R. H. 2003. The use of FRP composites in enhancing the structural behavior of timber beams, Journal of Reinforced Plastics and Composites 22(15): 1373-1388. http://dx.doi.org/10.1177/073168403035583

Li, Y.-F.; Xie, Y.-M.; Tsai, M.-J. 2009. Enhancement of the flexural performance of retrofitted wood beams using CFRP composite sheets, Construction and Building Materials 23(1): 411-422.

http://dx.doi.org/10.1016/j.conbuildmat.2007.11.005

Lopez-Anido, R.; Karbhari, V. M. 2000. Fiber reinforced composites in civil infrastructure, in Lopez-Anido, R.; Naik, T. R. (Eds). Emerging materials for civil engineering

infrastructure: state of the art. Reston (VA): ASCE Press, 41-78 [Chapter 2].

Lopez-Anido, R.; Xu, H. 2002. Structural characterization of hybrid FRP-glulam panels for bridge decks, Journal of Composites for Construction ASCE 6(3): 194-203. http://dx.doi.org/10.1061/(ASCE)1090-0268(2002)6: 3(194)

Lopez-Anido, R.; Michael, A. P.; Sandford, T. C. 2003. Experimental characterization of FRP composite-wood pile structural response by bending tests, Marine Structures 16(4): 257-274.

http://dx.doi.org/10.1016/S0951-8339(03)00021-2
Mostofinejad, D.; Mahmoudabadi, E. 2010. Grooving as an alternative method of surface preparation to postpone debonding of FRP laminates in concrete beams, Journal of Composites for Construction ASCE 14(6): 804-812. http://dx.doi.org/10.1061/(ASCE)CC.1943-5614.0000117

Naghipour, M.; Taheri, F.; Zou, G. 2005. Evaluation of vibration damping of glassreinforced-polymer-reinforced glulam composite beams, Journal of Structural Engineering ASCE 131(7): 1044-1050. http://dx.doi.org/10.1061/(ASCE)0733-9445(2005)131: 7(1044)

Naghipour, M.; Nematzadeh, M.; Yahyazadeh, Q. 2011. Analytical and experimental study on flexural performance of WPC-FRP beams, Construction and Building Materials 25(2): 829-837. http://dx.doi.org/10.1016/j.conbuildmat.2010.06.104

Naghipour, M.; Lale Arefi, S. H.; Nematzadeh, M. 2013. Performance of longitudinal grooves to prevent debonding of GFRP sheets used for the reinforcement of WPC beams, European Journal of Environmental and Civil Engineering 17(9): 761-776. http://dx.doi.org/10.1080/19648189.2013.815136

Ogawa, H. 2000. Architectural application of carbon fibres: development of new carbon fiber reinforced glulam, Carbon 38(2): 211-226. http://dx.doi.org/10.1016/S0008-6223(99)00146-3

Pantelides, C. P.; Romero, P.; Reaveley, L. D. 2010. Rehabilitation of splice connections of wood trusses with FRP composites, Construction and Building Materials 24(1): 3745. http://dx.doi.org/10.1016/j.conbuildmat.2009.08.007

Simonsen, J. 1995. The mechanical properties of woodfiberplastic composites, theoretical vs. experimental, in Proc. of Woodfiber Plastic Composites 7293: 47-55.

Taheri, F.; Zou, G.; Naghipour, M. 2005. Experimental and theoretical investigations into the energy absorption response of GFRP-strengthened glulam beams under impact loading, Forest Products Journal 55(4): 62-70.

Toutanji, H.; Ortiz, G. 2001. The effect of surface preparation on the bond interface between FRP sheets and concrete members, Composite Structures 53(4): 457-462. http://dx.doi.org/10.1016/S0263-8223(01)00057-5

Shahin LALE AREFI. Department of Civil Engineering, Shomal University, Iran. Research interests: civil engineering, earthquake engineering, experimental, composite materials, retrofitting and strengthening on steel and concrete structures, modelling and analytical research on steel and composite structural, multiple criteria decision making.

Morteza NAGHIPOUR. Associate Professor at the Faculty of Civil Engineering, Babol University and Technology, Iran. Research interests: offshore platforms (evaluation of behaviour), estimation of hydrodynamics forces on offshore structures, retrofitting and strengthening on steel structures, composite materials and their application on steel structures (and offshore structures), experimental, modelling and analytical research on steel and composite structural connections, shear walls and sandwich panels (evaluation of their seismic behaviour on duel systems).

Zenonas TURSKIS. Prof Dr at the Department of Construction Technology and Management, Vilnius Gediminas Technical University. Research interests: civil engineering, management, economics, OR, MCDM.

Mehdi NEMATZADEH. Assistant Professor at the Department of Civil Engineering, Mazandaran University, Iran. Research interests: retrofitting and strengthening on steel and concrete structures, composite materials, experimental, modelling and analytical research on composite structural, shear walls and sandwich panels. 